\title{
Investigation of the Pharmacokinetics of the ABCG2 Transporter Inhibi- tor Ko134 in Mice by a Newly Developed and Validated HPLC Method
}

\author{
Anita Sztojkov-Ivanov ${ }^{1}$, Orsolya Szolomajer-Csikós ${ }^{2}$, Árpád Márki ${ }^{1}$, Gábor K. Tóth ${ }^{2}$ and \\ István Zupkó ${ }^{1, *}$
}

${ }^{I}$ Department of Pharmacodynamics and Biopharmacy, University of Szeged, H-6720 Szeged, Eötvös u. 6, Hungary;
${ }^{2}$ Department of Medical Chemistry, University of Szeged, H-6720 Szeged, Dóm tér 8, Hungary

\begin{abstract}
Transporters belonging in the ATP-binding cassette (ABC) family are crucially involved in the determination of the pharmacokinetic behavior of xenobiotics and in the development of drug resistance. The targeting of these transporters has been accepted as a rational option via which to modify the absorption or distribution of pharmaceutical agents and to combat $\mathrm{ABC}$-related inefficiency. Inhibitors of the breast cancer resistance protein (BCRP/ABCG2) multidrug transporter are of interest as chemosensitizers for clinical drug resistance, for improving the pharmacokinetics of substrate chemotherapeutic drugs, and in functional assays of BCRP activity for tailoring chemotherapy. In this study, a reversephase high-performance liquid chromatographic method was developed for the determination of a simplified fumitremorgin $\mathrm{C}$ analog, Ko134, a potent ABCG2 inhibitor, in murine serum. The assay involves a simple sample preparation step followed by chromatographic separation on a C8 reversed-phase analytical column. The calibration plots were linear over the range 0.1 to $10 \mu \mathrm{g} / \mathrm{ml}(r>0.99)$. The limits of detection and quantification were $10 \mathrm{ng} / \mathrm{ml}$ and $50 \mathrm{ng} / \mathrm{ml}$, respectively. The validation results demonstrated that the method is precise, accurate and selective for the determination of Ko134 in mouse serum. The method was successfully applied to evaluate the pharmacokinetic parameters of Ko134 after different modes of administration in mice.
\end{abstract}

Keywords: Drug administration, HPLC, Ko134, mouse serum, pharmacokinetics, validation.

\section{INTRODUCTION}

The ATP-binding cassettes (ABCs) are the largest family of transmembrane proteins and have been at the center of interest for many years. As primary active transporters, these proteins translocate a wide variety of substrates, including metabolic products, nutrients and drugs across extra- and intracellular membranes at the expense of ATP hydrolysis. The members of the family are encoded by 48 genes in humans, but only around 9 of them have a substantial impact on the pharmacokinetic behavior of drugs [1]. One of these crucial $\mathrm{ABCs}$ is the breast cancer resistance protein (BCRP/ABCG2), identified in 1998 in a resistant variant of breast cancer cell line MCF-7 [2]. ABCG2, also known as the placenta-specific $\mathrm{ABC}$ transporter (ABCP) [3] or mitoxantrone-resistance gene [4], is expressed in stem cells in all of the major tissues of the body [5], but is principally localized to the apical surface of the intestinal enterocytes, the luminal surface of the liver canaliculi and the proximal convoluted tubule of the kidneys and the blood-brain, blood-testis, blood-placental and blood-retinal barriers [6]. BCRP functions as a defense mechanism in human physiology by limiting the absorption of pharmaceutical agents and toxic substrate molecules and also plays an active role in the secretion of drugs and xenobiotics by facilitating excretion.

*Address correspondence to this author at the Department of Pharmacodynamics and Biopharmacy, University of Szeged, H-6720 Szeged, Eötvös u. 6., Hungary; Tel: +36-62-546839; Fax: +36-62-545567;

E-mail: zupko@pharm.u-szeged.hu
Since BCRP is located on the secretory surface of the major organs involved in the absorption (the small intestine), distribution (the placenta and various barriers) and elimination (the liver and small intestine) of drugs, it alters the bioavailability and pharmacokinetics of substrate drugs. Functional characterization has demonstrated that BCRP can transport a wide range of substrates, such as common dietary xenobiotics and chemotherapeutics, including mitoxantrone, topotecan, doxorubicin [7], daunorubicin [8], danusertib [9], irinotecan and its SN-38 metabolite [10] and imatinib [11].

Besides $\mathrm{ABCB} 1$ and $\mathrm{ABCC} 1, \mathrm{ABCG} 2$ is one of the proteins that is overexpressed upon exposure to toxic compounds responsible for the development of multidrug resistance. The expression of BCRP has been detected in numerous types of human cancers, including hematological malignancies and solid tumors. The phenomenon of multidrug resistance is one of the major problems faced by anticancer chemotherapy. Based on their crucial biological functions all kinds of uptake and efflux transporters represent attractive targets for drug discovery with a broad variety of indications $[12,13]$. The development of highly specific inhibitors of BCRP as chemosensitizers could improve the pharmacokinetics and therefore the efficacy of substrate chemotherapeutic drugs. The mycotoxin fumitremorgin $\mathrm{C}$ (FTC), isolated from Aspergillus fumigatus, was identified as a specific reversal agent for the BCRP transporter [14, 15], but it exhibited toxic effects on the central nervous system inducing tremor activity in mice and other animals 
A

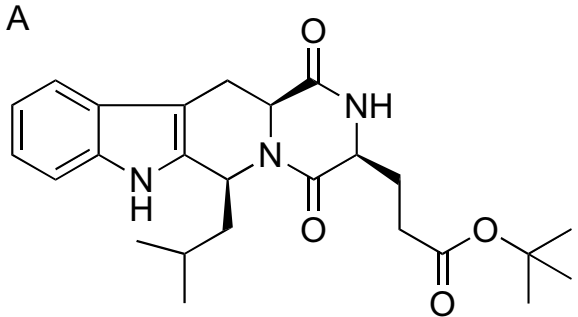

B<smiles>[B]C(=O)O</smiles>

Fig. (1). Chemical structures of Ko134 (A) and 1-isobutyl-2,3,4,9-tetrahydro-1H- $\beta$-carboline-3-carboxylic acid acetate (B).

[16]. The simplified FTC analog Ko134 (Fig. 1) has a much more potent ABCG2 inhibitory effect than that of FTC itself with improved selectivity and specificity, while displaying low in vivo toxicity $[17,18]$. Ko134 is therefore a commonly utilized reference compound in in vitro studies. However, since its pharmacokinetic profile is poorly characterized, it has been inadequately evaluated in in vivo settings. We are not aware of any analytical method that has been developed and validated for measurement of the concentration of Ko134 in animal serum. In this study, therefore, we developed and validated a sensitive HPLC assay with which to quantify Ko134 in mouse serum, and used this assay to characterize the basic pharmacokinetic parameters of Ko134 in mice.

\section{EXPERIMENTAL}

\subsection{Chemicals and Materials}

Ko134 (3-[(3S,6S,12aS)-6-isobutyl-1,4-diketo-2,3,6,7,12, $12 \mathrm{a}-\mathrm{h}$ exahydropyrazino $[1,2-\mathrm{b}]-\beta$-carbolin-3-yl]propionic acid tert-butyl ester) was synthetized as published previously [19]. 1-Isobutyl-2,3,4,9-tetrahydro- $1 H$ - $\beta$-carboline-3-carboxylic acid acetate (internal standard, IS) was purchased from Sigma-Aldrich (Budapest, Hungary). Their chemical structures are illustrated in (Fig. 1). Potassium dihydrogenphosphate of analytical grade was obtained from Molar Chemicals (Budapest, Hungary). Orthophosphoric acid of HPLC grade was from Sigma-Aldrich (Budapest, Hungary). HPLCgrade acetonitrile and methanol were purchased from Merck (Darmstadt, Germany). The water was purified and deionized with a Milli-Q system (Millipore, Milford, MA, USA). All other chemicals were of analytical grade and were purchased from Sigma-Aldrich (Budapest, Hungary).

\subsection{Instrumentation}

The HPLC apparatus consisted of a Shimadzu system (Shimadzu Corporation, Kyoto, Japan) equipped with a solvent delivery system (LC-20AD), a DGU-20A 3 on-line degasser, a CTO-20A column oven, an SPD-M20A photodiode-array detector, an RF-10A XL fluorescence detector and a CBM-20A system controller. The chromatographic system was involved a Rheodyne Model 7125 injector (Cotati, CA, USA) with a $20-\mu 1$ loop. The system control and data acquisition were performed with Shimadzu "LC solution" software (Shimadzu Corporation, Kyoto, Japan).

\subsection{Liquid Chromatographic Conditions}

The chromatographic separations were performed on a Kromasil KR100-5C8-150A 5- $\mu \mathrm{m}, 250-\mathrm{mm} \times 4.6-\mathrm{mm}$ analytical column (Hichrom, Berkshire, UK), protected by a 5 um Kromasil C8 guard column. The column temperature was kept constant at $35^{\circ} \mathrm{C}$. Separations were performed in isocratic mode. The mobile phase used for the separation consisted of $0.025 \mathrm{M}$ potassium dihydrogenphosphate buffer $(\mathrm{pH} 2.7)$ :acetonitrile $(50: 50, \mathrm{v} / \mathrm{v})$ pumped at a flow rate of $0.8 \mathrm{ml} / \mathrm{min}$. The mobile phase was filtered by a Millipore vacuum filtration system equipped with a $0.45-\mu \mathrm{m}$ pore size filter and degassed by ultrasonication. The fluorescence detector was set at $235 \mathrm{~nm}$ as excitation wavelength and 300 $\mathrm{nm}$ as emission wavelength.

\subsection{Preparation of Stock and Working Solutions}

Primary stock solutions of Ko134 and the IS were prepared in a concentration of $0.5 \mathrm{mg} / \mathrm{ml}$ in acetonitrile. The stock solution of Ko134 was further diluted in acetonitrile to obtain an intermediate concentration of $50 \mu \mathrm{g} / \mathrm{ml}$. The working standard solutions of Kol34 (1-50 $\mu \mathrm{g} / \mathrm{ml})$ required for serum spiking and quality control (QC) samples were subsequently obtained by dilution from the primary and intermediate stock solutions. The $0.5 \mathrm{mg} / \mathrm{ml}$ stock solution of the IS was further diluted with acetonitrile to yield a working solution of $0.05 \mathrm{mg} / \mathrm{ml}$. All acetonitrile solutions were stored at $-20{ }^{\circ} \mathrm{C}$, protected from the light, until used.

\subsection{Preparation of Calibration and Quality Control Standards}

Drug-free control mouse serum was spiked with portions of working standard solutions of Ko134 to provide calibration standards in the range $0.1-10 \mu \mathrm{g} / \mathrm{ml}$. QC samples were prepared by spiking drug-free control mouse serum with working standard solutions to provide samples at three different concentrations of Ko134, low (LQC $=0.2 \mu \mathrm{g} / \mathrm{ml}$ ), medium $(\mathrm{MQC}=5 \mu \mathrm{g} / \mathrm{ml})$ and high $(\mathrm{HQC}=8 \mu \mathrm{g} / \mathrm{ml})$, from a weighing independent of those used for preparing the calibration curves. Aliquots $(0.2 \mathrm{ml})$ from the bulk QC solutions were transferred into Eppendorf tubes and stored at $-20{ }^{\circ} \mathrm{C}$ until analysis.

\subsection{Serum Sample Pretreatment}

Mouse serum samples were fully thawed at room temperature and vortexed adequately. Aliquots of mouse serum $(0.2 \mathrm{ml})$ were spiked with $20 \mu \mathrm{l}$ of the IS solution $(0.05$ $\mathrm{mg} / \mathrm{ml}$ ) and mixed with $1.2 \mathrm{ml}$ of methanol to precipitate the proteins, vortexed for $1 \mathrm{~min}$ and centrifuged for $10 \mathrm{~min}$ at $12,000 \mathrm{~g}$. The supernatants were transferred to a set of clean glass tubes and evaporated to dryness under a stream of nitrogen at $40^{\circ} \mathrm{C}$. Each residue was reconstituted in $200 \mu \mathrm{l}$ of mobile phase and vortex-mixed for $10 \mathrm{~s} ; 20 \mu \mathrm{l}$ of solution was injected for analysis. 


\subsection{Validation of the Method}

The HPLC method was validated according to the guidelines for bioanalytical method validation laid down by the FDA [20].

\subsubsection{Specificity and Selectivity}

The specificity and selectivity of the method were assessed by screening different sources of blank mouse serum for endogenous interferences in the retention time of Ko134. Chromatograms of blank samples were compared with those of serum samples spiked with Ko134 and IS, and serum samples obtained from mice after the administration of Ko134.

\subsubsection{Linearity}

The linearity range of the method for Ko134 in serum was evaluated by means of seven-point standard plots in the concentration range $0.1-10 \mu \mathrm{g} / \mathrm{ml}$ on three validation days. Serum calibration curves were constructed by plotting the peak area ratio of Ko134 against the IS peak area vs. analyte concentration using linear regression. The calibration curves were evaluated from the aspects of their correlation coefficients, slopes and intercepts. Analysis of variance (ANOVA) was used to assess significant differences at 5\% significance level. The data analysis MS Excel software (2007) was employed in all statistical analyses of calibration. The calibration curves were evaluated from the aspects of their correlation coefficients, slopes and intercepts. The concentrations at the limit of detection (LOD) and the lower limit of quantitation (LOQ) were empirically determined during the evaluation of the linear range of the calibration curve [21]. The LOD of an individual analytical procedure is the lowest amount of analyte in a sample that can be detected, but not necessarily quantitated as an exact value. The LOQ is the lowest amount of analyte in a sample that can be quantitatively determined with a precision with CV less than $20 \%$ and accuracy within $15 \%$ of the nominal value. The accuracy of calibration standards was required to be within \pm $15 \%$ of the nominal concentration, except at the LOQ, where it was required to be within $\pm 20 \%$.

\subsubsection{Precision and Accuracy}

The intra-day precision and accuracy of the method for the quantification of Ko134 were determined by analysis of five sets of serum QC samples at the LQC, MQC and HQC levels in a single day. The inter-day precision and accuracy were estimated by analysis of all QC samples over five validation days. Accuracy was calculated as the mean percentage deviation (RE) of the observed concentration $\left(C_{\mathrm{obs}}\right)$ from the nominal concentration $\left(C_{\mathrm{nom}}\right)$ at each QC level: \% RE = $\left[\left(C_{\text {obs }}-C_{\text {nom }}\right) / C_{\text {nom }}\right] \times 100$. Precision was expressed as a percentage of the coefficient of variation: $\% \mathrm{CV}=(\mathrm{SD} /$ mean $\left.C_{\mathrm{obs}}\right) \times 100$. The criteria for acceptability were that the intraand inter-assay accuracies and precisions should be within \pm $20 \%$ at the LOQ level and within $\pm 15 \%$ at other concentrations.

\subsubsection{Recovery}

The recovery from serum was carried out in QC samples at the LQC, MQC and HQC levels. The absolute percentage recovery was determined by comparing the mean peak area of three replicates of $\mathrm{MeOH}$-treated samples with the mean peak areas of non-treated standards of equivalent concentration: $\% \mathrm{AR}=$ (peak area sample/peak area standard) $\mathrm{x} 100$.

\subsubsection{Stability}

The freeze-thaw stability of Ko134 in mouse serum was evaluated through the use of QC samples at three concentration levels, which were maintained at the storage temperature $\left(-70^{\circ} \mathrm{C}\right)$ for $24 \mathrm{~h}$ and then thawed at room temperature. When completely thawed, the samples were refrozen for 24 $\mathrm{h}$ under the same conditions. The freeze-thaw cycles were repeated three times before sample preparation and analysis.

For the short-term stability study, QC serum samples were kept at room temperature for a period that exceeded the routine preparation time of the samples $(24 \mathrm{~h})$. The longterm stability of Ko134 in mouse serum was assessed by analyzing QC samples stored at $-70{ }^{\circ} \mathrm{C}$ for 1 month. The stability of the Ko134 stock solution was evaluated at room temperature for 3 days.

The peak areas of Ko134 at the initial concentrations at different QC levels were used as reference to determine the relative stability of Ko134 in the experiments described above.

\subsection{Pharmacokinetic Study}

The pharmacokinetic study was carried out with male CFLP mice (Toxi-Coop, Budapest, Hungary) aged 6 weeks, weighing 24-30 g, which were allowed to acclimate for 1 week before the study. The animals were fasted overnight $(\sim 16 \mathrm{~h})$ before drug administration, but had free access to water throughout the experimental period. They were given standard rodent food (Bioplan, Isaszeg, Hungary) $2 \mathrm{~h}$ after drug administration. The mice were randomized into 3 groups of 5 animals each for the different treatments. Group 1 was treated with a $30 \mathrm{mg} / \mathrm{kg}$ intravenous (iv) bolus of Ko134 in a solvent system via the tail vein; the mice in Group 2 received $50 \mathrm{mg} / \mathrm{kg} \mathrm{Ko} 134$ orally by gavage; and Group 3 received the dose of $50 \mathrm{mg} / \mathrm{kg}$ intraperitoneally (ip). The solvent system in which Ko134 was dissolved was $90 \%$ physiological saline, $5 \%$ Cremophor, $5 \%$ dimethylsulfoxide and all treatments were administered in a dosing volume of $10 \mathrm{ml} / \mathrm{kg}$. 15, 30, 60, 120 and $240 \mathrm{~min}$ after the Ko134 treatment, the mice were anesthetized with isoflurane, and blood was collected by cardiac puncture and centrifuged at $5000 \mathrm{~g}$ for $10 \mathrm{~min}$ to obtain serum. Additional samples were collected 20 and 45 min after the ip administration. Samples were stored at $-70{ }^{\circ} \mathrm{C}$ until analysis. All experiments involving animal subjects were carried out with the approval of the Hungarian Ethics Committee for Animal Research (registration number: IV/01758-2/2008).

\subsection{Data Analysis}

The figures of HPLC chromatograms were produced using gnuplot 4.6 (Ubuntu 12.04), the pharmacokinetic parameters were calculated by means of PKSolver using noncompartmental analyses module [22]. The data analysis module of MS Excel 2007 was used to perform ANOVA analysis of the HPLC calibration. One-way ANOVAs were used to test if the slopes were significantly different from zero, with the level of significance set at $\mathrm{p}<0.05$. 


\section{RESULTS AND DISCUSSION}

\subsection{Development of the Chromatographic Conditions}

HPLC separations were initially tested on two types of reversed phase columns, an ACE C8 $(250 \mathrm{~mm} \times 4.6 \mathrm{~mm}, 5$ $\mu \mathrm{m}$; Advanced Chromatography Technologies, Aberdeen, Scotland) and a Kromasil C8 $(250 \mathrm{~mm} \times 4.6 \mathrm{~mm}, 5 \mu \mathrm{m}$, Hichrom, Berkshire, UK) analytical column with mixtures of phosphate buffer at pH 2.7 and $\mathrm{MeCN}$ as eluents. The Kromasil column provided better peak shapes/symmetry combined relatively shorter retention times and was used for further analysis. The best chromatographic condition was obtained with $0.025 \mathrm{M}$ potassium dihydrogenphosphate buffer ( $\mathrm{pH}$ 2.7): $\mathrm{MeCN}(50: 50, \mathrm{v} / \mathrm{v})$ at a flow rate of $0.8 \mathrm{ml} / \mathrm{min}$. The UV-vis absorbance of Ko134 was recorded from wavelenght of 190-800 nm with the Shimadzu SPD-M20A photodiode-array detector. The absorption maximums of Ko134 were at $223 \mathrm{~nm}$ and $274 \mathrm{~nm}$. Therefore, wavelenght of 235 $\mathrm{nm}$ was chosen for UV detection in this assay. After deproteinization of serum samples, the sensitivity at the optimal UV wavelenght would not be sufficient because of the low concentration of Ko134 in mice, thus fluorescence detection was selected for this study. As the absorptium maximum is almost identical with the excitation maximum of the analyte, the excitation wavelenght is typically choosen close to the absorption maximum, namely $225 \mathrm{~nm}$. An excellent fluorescent yield was acquired at $300 \mathrm{~nm}$, selected as the optimal emission wavelenght. In summary, the best chromatographic condition was obtained with $0.025 \mathrm{M}$ potassium dihydrogenphosphate buffer ( $\mathrm{pH} 2.7)$ : $\mathrm{MeCN}(50: 50, \mathrm{v} / \mathrm{v})$ pumped at flow rate of $0.8 \mathrm{ml} / \mathrm{min}$ using a Kromasil KR100-5C8-150A $(5 \mu \mathrm{m}, 250 \mathrm{~mm} \times 4.6 \mathrm{~mm}$ ) analytical column (Hichrom, Berkshire, UK), with fluorescence detection at excitation wavelenght of $235 \mathrm{~nm}$ and emission wavelenght of $300 \mathrm{~nm}$, temperature at $35^{\circ} \mathrm{C}[23]$.

\subsection{Specificity and Selectivity}

The analysis of drug-free serum from six individual blank samples revealed that there were no interfering peaks of endogenous substances at the retention times of Ko134 and the IS, indicating the specificity of the method. With the chromatographic system described, the retention times for Ko134 and the IS were $16.04 \pm 0.5 \mathrm{~min}$ and $14.41 \pm 0.4 \mathrm{~min}$, respectively. (Fig. 2) represents chromatograms of blank mouse serum, serum spiked with the IS and Ko134, and an experimental mouse serum sample collected $30 \mathrm{~min}$ after iv treatment with $30 \mathrm{mg} / \mathrm{kg}$ of Ko134.

\subsection{Linearity}

Seven-point calibration plots were constructed for Ko134 at concentrations of $0.1,0.2,0.5,1,2,5$ and $10 \mu \mathrm{g} / \mathrm{ml}$ for three consecutive days. Under the described chromatographic conditions, a linear relationship with a good correlation coefficient $(r=0.9969 \pm 0.0031, n=3)$ was found between the peak area ratio of Ko134 against the IS peak area vs. analyte concentration in the calibration concentration range. The regression equation of the calibration plot was $y=$ $1245280.35 x \pm 10916$, the relative standard deviation of the slope was $1.30 \%$ (ANOVA; $<<0.05)$. The LOQ, defined as the quantity that was 10 -fold above the background noise and that could be determined with acceptable precision and accuracy, was found to be $50 \mathrm{ng} / \mathrm{ml}$ for Ko134 in mouse serum samples. The mean percentage accuracy was $95 \%$ and the precision was below $10 \%$. The LOD was $10 \mathrm{ng} / \mathrm{ml}$ with a signal-to-noise ratio of 3 .

\subsection{Precision and Accuracy}

The results relating to the accuracy and precision are shown in Table 1. The intra- and inter-day accuracies for Ko134 at the $0.2,5$ and $8 \mu \mathrm{g} / \mathrm{ml}$ levels in mouse serum fell in the ranges $94.30-106.9 \%$ and $95.1-101.24 \%$, and the intraand inter-day precisions (CV\%) were in the ranges $4.6-9.3 \%$ and $7.1-8.9 \%$, respectively. These data indicated that the repeatability, intermediate precision and bias values of the assay were within the acceptance limits of $\pm 15 \%$ at all QC concentration levels, and the validated assay was therefore precise, accurate and reproducible.

\subsection{Recovery}

The mean extraction recoveries of Ko134 at concentrations of $0.2,5$ and $8 \mu \mathrm{g} / \mathrm{ml}$ were $98.6 \pm 2.0 \%, 100.5 \pm 5.8 \%$ and $101.3 \pm 4.7 \%$, respectively (Table 1 ). The mean recovery of the IS was $96.7 \%$, with $\mathrm{CV}=1.8 \%$. The results showed that there was no substantial difference in the signals of the analytes extracted from mouse serum and the non-extracted standard solutions.

\subsection{Stability}

Data on the stability of Ko134 during sample handling (freeze-thaw, short-term, long-term and stock solution) are given in Table 2. Ko134 at all QC levels was stable in mouse serum for at least $24 \mathrm{~h}$ at room temperature, during three freeze-thaw cycles, and during storage at $-70{ }^{\circ} \mathrm{C}$ for 1 month. The high stability of Ko134 in mouse serum suggested that no special care was needed during sample preparation and a large batch of samples could be processed at one time within $24 \mathrm{~h}$, a situation satisfying the requirements of efficient and fast analysis.

\subsection{Pharmacokinetic Study of Ko134 in Mice}

The method described above was successfully applied to quantify the serum concentrations of Ko134 in the pharmacokinetic study after iv, oral or ip administration to mice. The mean serum concentration-time profiles are shown in (Fig. 3). The basic pharmacokinetic parameters of Ko134 in mice calculated with the PKSolver 2.0 software in the noncompartmental approach [19] are listed in Table 3. As shown in (Fig. 3), the pharmacokinetic profile of Ko134 after the iv bolus injection $(30 \mathrm{mg} / \mathrm{kg})$ points to a first-order kinetic process in mice, with a two-phase exponential elimination suggesting its distribution in two compartments. After ip administration $(50 \mathrm{mg} / \mathrm{kg})$, Ko134 was rapidly absorbed; substantial serum concentrations were detected $20 \mathrm{~min}$ after injection and $\mathrm{T}_{\max }$ was found at $30 \mathrm{~min}$. The compound is rapidly eliminated independently of the mode of delivery $\left(t_{1 / 2}\right.$ $\sim 40-60 \mathrm{~min}$ and $\mathrm{CL} \sim 66 \mathrm{ml} / \mathrm{min}$ ), indicating the need for multiple administration when continuous blockade of the ABCG2 transporter is expected in mice. The calculated parameters suggest that Ko134 exhibits high clearance and a high volume of distribution in mice. Since the volume of distribution is substantially higher than the total water 

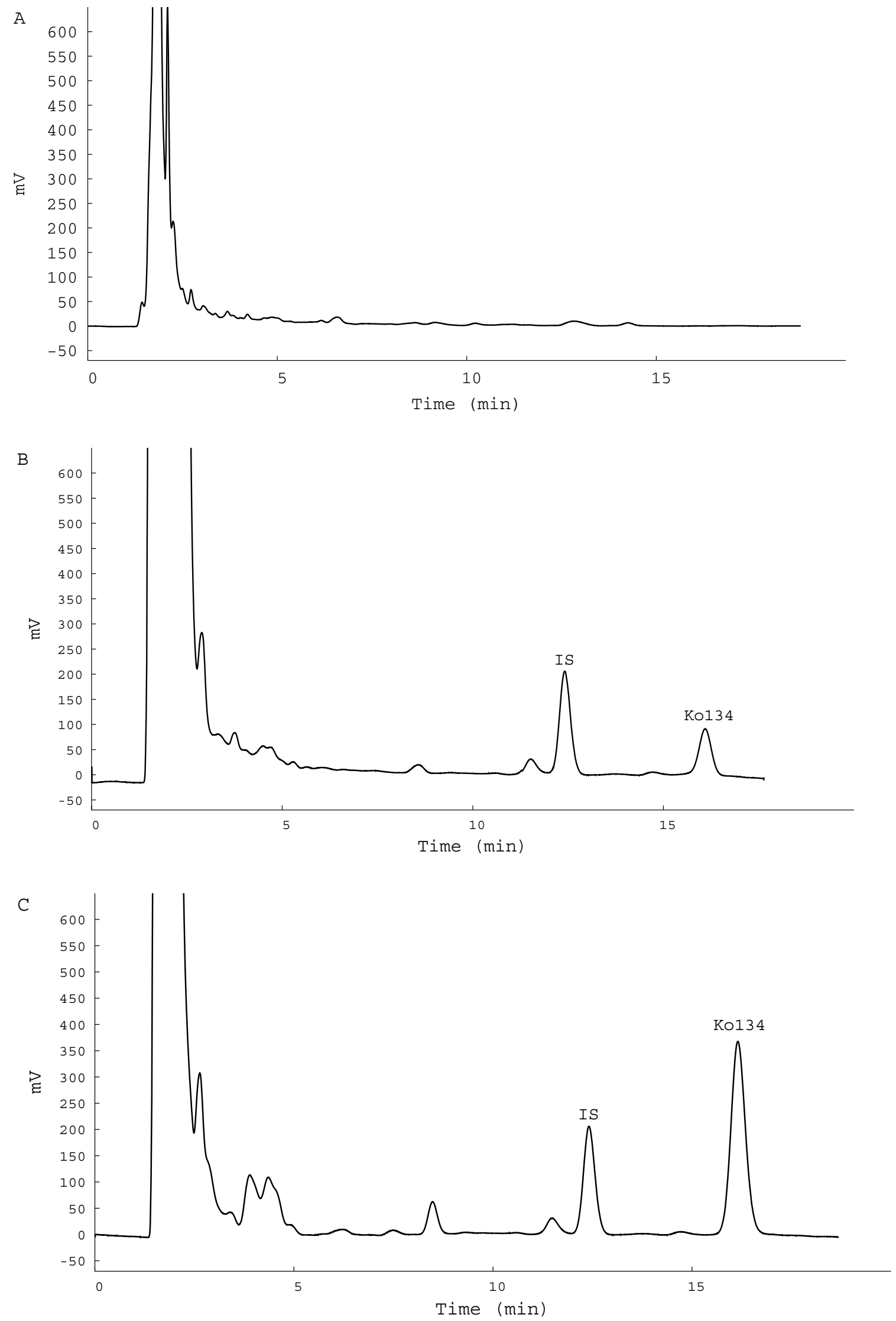

Fig. (2). Representative chromatograms of blank mouse plasma (A); blank mouse serum spiked with $5 \mu \mathrm{g} / \mathrm{ml} \mathrm{Ko134} \mathrm{and} 5 \mu \mathrm{g} / \mathrm{ml} \mathrm{IS} \mathrm{(B);} \mathrm{and}$ a mouse serum sample at $30 \mathrm{~min}$ after a single iv administration of $30 \mathrm{mg} / \mathrm{kg} \mathrm{Ko134} \mathrm{spiked} \mathrm{with} 5 \mu \mathrm{g} / \mathrm{ml}$ IS (C). 
Table 1. Accuracy, precision and recovery of values of Ko134 QC samples in mouse serum.

\begin{tabular}{|c|c|c|c|}
\hline & \multicolumn{3}{|c|}{ Spiked Ko134 Concentration $(\mu \mathrm{g} / \mathrm{ml})$} \\
\hline \multicolumn{4}{|l|}{ Accuracy and precision } \\
\hline \multicolumn{4}{|l|}{ Intra-day precision $(n=5)$} \\
\hline Measured concentration (mean \pm S.D.; $\mu \mathrm{g} / \mathrm{ml}$ ) & $0.1886 \pm 0.0176$ & $5.2580 \pm 0.4329$ & $8.5590 \pm 0.3988$ \\
\hline \multicolumn{4}{|l|}{ Inter-day precision $(n=5)$} \\
\hline Measured concentration (mean \pm S.D.; $\mu \mathrm{g} / \mathrm{ml}$ ) & $0.1902 \pm 0.0171$ & $5.0620 \pm 0.4385$ & $7.9460 \pm 0.5708$ \\
\hline Accuracy $(\%)$ & 95.1 & 101.2 & 99.3 \\
\hline $\mathrm{CV}(\%)$ & 8.9 & 8.6 & 7.1 \\
\hline CV $(\%)$ & 2.0 & 5.7 & 4.6 \\
\hline
\end{tabular}

Table 2. Stability values of Ko134 samples under various experimental conditions.

\begin{tabular}{|c|c|c|}
\hline QC Sample ( $\mu \mathrm{g} / \mathrm{ml})$ & Stability Condition & $\%$ Remaining \pm S.D. \\
\hline \multirow{3}{*}{0.2} & 3 freeze-thaw cycles & $95.7 \pm 4.5$ \\
\hline & Long-term $\left(-70^{\circ} \mathrm{C}, 30\right.$ days $)$ & $98.2 \pm 3.5$ \\
\hline & Stock solution (room temperature, 3 days) & $97.9 \pm 6.8$ \\
\hline \multirow{3}{*}{5.0} & Short-term (room temperature, $24 \mathrm{~h}$ ) & $100.2 \pm 3.0$ \\
\hline & Long-term $\left(-70^{\circ} \mathrm{C}, 30\right.$ days $)$ & $102.4 \pm 4.1$ \\
\hline & Stock solution (room temperature, 3 days) & $105.0 \pm 5.9$ \\
\hline \multirow{2}{*}{8.0} & 3 freeze-thaw cycles & $99.7 \pm 4.0$ \\
\hline & Short-term (room temperature, $24 \mathrm{~h}$ ) & $102.7 \pm 2.2$ \\
\hline
\end{tabular}

A

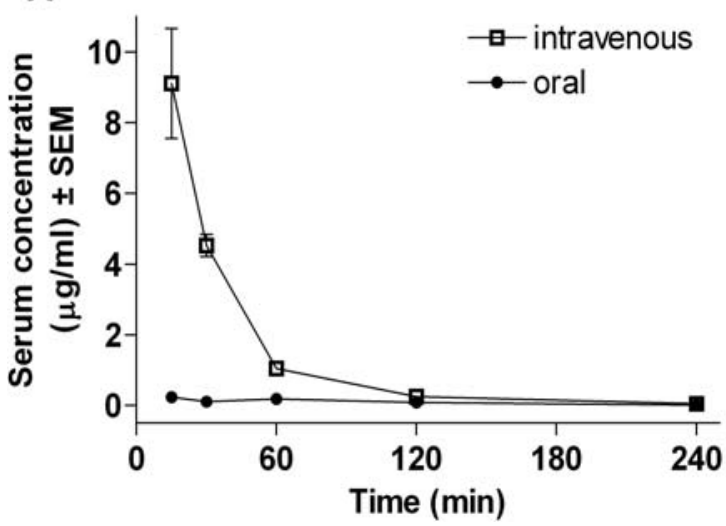

B

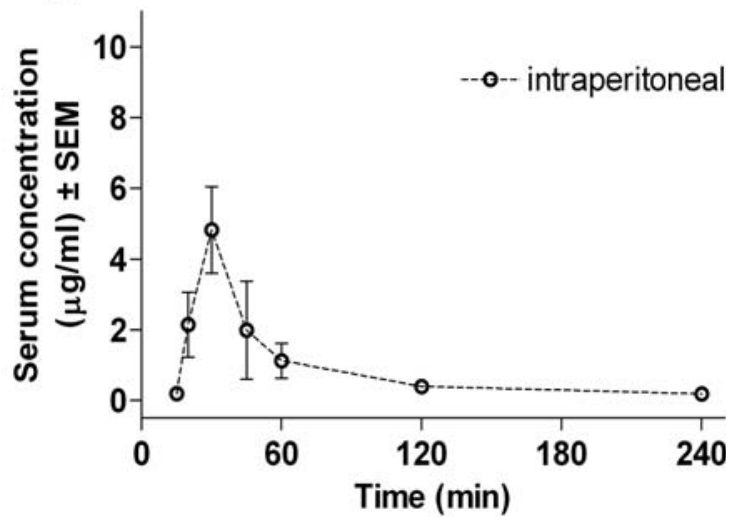

Fig. (3). Mean serum concentration-time profiles of Ko134 following a single intravenous (30 mg/kg), oral (50 mg/kg) (panel A) or intraperitoneal $(50 \mathrm{mg} / \mathrm{kg}$ ) (panel B) administration in male CFLP mice (mean $\pm \mathrm{SEM}, n=5$ for all). 
Table 3. Calculated pharmacokinetic parameters of Ko134 in mice after different administration routes.

\begin{tabular}{|c|c|c|}
\hline \multirow{2}{*}{ Parameter } & \multicolumn{2}{|c|}{ Route of Administration } \\
\cline { 2 - 3 } & Intravenous (30 $\mathbf{~ g /} / \mathbf{k g})$ & 0.0115 \\
\hline \hline Lambda_z $(1 / \mathrm{min})$ & 0.0168 & 196.95 \\
\hline $\mathrm{AUC}_{0-\mathrm{t}}(\mathrm{min} \mu \mathrm{g} / \mathrm{ml})$ & 448.37 & 212.70 \\
\hline $\mathrm{AUC}_{0-\infty}(\mathrm{min} \mu \mathrm{g} / \mathrm{ml})$ & 451.14 & 60.37 \\
\hline $\mathrm{T}_{1 / 2}(\mathrm{~min})$ & 41.20 & 66.50 \\
\hline $\mathrm{CL}_{(\mathrm{ml} / \mathrm{min})}$ & 66.50 & 5792.28 \\
\hline$V_{\mathrm{d}}(\mathrm{ml})$ & 3952.3 & 28.29 \\
\hline$F(\%)$ & - & $\mathbf{2}$ \\
\hline
\end{tabular}

Data were calculated by using noncompartmental analysis. Lambda $z$ : elimination constant; $\mathrm{AUC}_{0} \rightarrow \mathrm{t}:$ area under the concentration-time curve from time 0 to 240 min; $\mathrm{AUC}_{0} \rightarrow \infty$ : area under the time-concentration curve from time 0 to infinity; $\mathrm{T}_{1 / 2}$ : elimination half-life; $V_{\mathrm{d}}$ : volume of distribution; CL: total clearance; $F$ : absolute bioavailability calculated from $\mathrm{AUC}_{0 \rightarrow \infty}$ values.

content of the animal most of the given amount is concentrated out of intravascular compartment. The physiological bioavailability calculated from the $\mathrm{AUC}_{0 \rightarrow \infty}$ values of ip injected Ko134 is relatively low $(28.29 \%)$, contraindicating this administration route in in vivo experimentation. Oral treatment with $50 \mathrm{mg} / \mathrm{kg} \mathrm{Ko} 134$ did not result in considerable serum concentrations, presumably as a consequece of the limited intestinal absorption or the extensive presystemic or hepatic first-pass metabolism, and therefore no kinetic parameters were calculated for this mode of administration.

\section{CONCLUSION}

The validated HPLC method presented here is suitable for the determination of the reference compound Ko134 in mouse serum and presumably other body fluids. Its simplicity and reliability make it ideal as a basis for the development of analytical methods for the quantitation of Ko134 in solid tissues, including experimentally induced cancer. Determination of the appropriate iv or ip dosage schedule of Ko134 is facilitated by the calculated pharmacokinetic parameters

\section{CONFLICT OF INTEREST}

The authors confirm that this article content has no conflict of interest.

\section{ACKNOWLEDGEMENTS}

The work was supported by the European Union and cofinanced by the European Social Fund (TÁMOP-4.2.2.A11/1/KONV-2012-0035).

\section{REFERENCES}

[1] Scherrmann, J.M. Transporters in absorption, distribution, and elimination. Chem. Biodivers., 2009, 6(11), 1933-1942.

[2] Doyle, L.A.; Yang, W.; Abruzzo, L.V.; Krogmann, T.; Gao, Y.; Rishi, A.K.; Ross, D.D. A multidrug resistance transporter from human MCF-7 breast cancer cells. Proc. Natl. Acad. Sci. U. S. A., 1998, 95(26), 15665-15670

[3] Allikmets, R.; Schriml, L.M.; Hutchinson, A.; Romano-Spica, V.; Dean, M. A human placenta-specific ATP-binding cassette gene (ABCP) on chromosome $4 \mathrm{q} 22$ that is involved in multidrug resistance. Cancer Res., 1998, 58(23), 5337-5339.
[4] Miyake, K.; Mickley, L.; Litman, T.; Zhan, Z.; Robey, R.; Cristensen, B.; Brangi, M.; Greenberger, L.; Dean, M.; Fojo, T.; Bates, S.E. Molecular cloning of cDNAs which are highly overexpressed in mitoxantrone-resistant cells: demonstration of homology to $\mathrm{ABC}$ transport genes. Cancer Res., 1999, 59(1), 8-13.

[5] Doyle, L.; Ross, D.D. Multidrug resistance mediated by the breast cancer resistance protein BCRP (ABCG2). Oncogene, 2003, 22(47), 7340-7358.

[6] Natarajan, K.; Xie, Y.; Baer, M.R.; Ross, D.D. Role of breast cancer resistance protein (BCRP/ABCG2) in cancer drug resistance. Biochem. Pharmacol., 2012, 83(8), 1084-1103.

[7] Allen, J.D.; Brinkhuis, R.F.; Wijnholds, J.; Schinkel, A.H. The mouse Bcrp1/Mxr/Abcp gene: amplification and overexpression in cell lines selected for resistance to topotecan, mitoxantrone, or doxorubicin. Cancer Res., 1999, 59(17), 4237-4241.

[8] Sargent, J.M.; Williamson, C.J.; Maliepaard, M.; Elgie, A.W.; Scheper, R.J.; Taylor, C.G. Breast cancer resistance protein expression and resistance to daunorubicin in blast cells from patients with acute myeloid leukaemia. Br. J. Haematol., 2001, 115(2), 257-262.

[9] Balabanov, S.; Gontarewicz, A.; Keller, G.; Raddrizzani, L.; Braig, M.; Bosotti, R.; Moll, J.; Jost, E.; Barett, C.; Rohe, I.; Bokemeyer, C.; Holyoake, T.L.; Brummendorf, T.H. Abcg2 overexpression represents a novel mechanism for acquired resistance to the multikinase inhibitor Danusertib in BCR-ABL-positive cells in vitro. PloS. One, 2011, 6(4), e19164.

[10] Kawabata, S.; Oka, M.; Shiozawa, K.; Tsukamoto, K.; Nakatomi, K.; Soda, H.; Fukuda, M.; Ikegami, Y.; Sugahara, K.; Yamada, Y.; Kamihira, S.; Doyle, L.A.; Ross, D.D.; Kohno, S. Breast cancer resistance protein directly confers SN-38 resistance of lung cancer cells. Biochem. Biophys. Res. Commun., 2001, 280(5), 1216-1223.

[11] Burger, H.; van Tol, H.; Boersma, A.W.; Brok, M.; Wiemer, E.A.; Stoter, G.; Nooter, K. Imatinib mesylate (STI571) is a substrate for the breast cancer resistance protein (BCRP)/ABCG2 drug pump. Blood, 2004, 104(9), 2940-2942.

[12] Stefan-van Staden, L.R.; Nejem, R.M.; van Staden, J.F.; AboulEnein, H.Y. Enantioselective, potentiometric membrane electrodes (EPME) based on maltodextrins for the determination of Lvesamicol in serum samples. Curr. Pharm. Anal., 2011, 7(4), 253257.

[13] Singhvi, G.; Gampa, G.; Saha, R.N. Development and validation of a stability indicating liquid chromatographic method for the determination of milnacipran in bulk and its formulations. Curr. Pharm. Anal., 2013, 9(2), 191-198.

[14] Rabindran, S.K.; He, H.; Singh, M.; Brown, E.; Collins, K.I.; Annable, T.; Greenberger, L.M. Reversal of a novel multidrug resistance mechanism in human colon carcinoma cells by fumitremorgin C. Cancer Res., 1998, 58(24), 5850-5858.

[15] Rabindran, S.K.; Ross, D.D.; Doyle, L.A.; Yang, W.; Greenberger, L.M. Fumitremorgin C reverses multidrug resistance in cells transfected with the breast cancer resistance protein. Cancer Res., 2000, $60(1), 47-50$ 
[16] Plate, R.; Hermkens, P.H.H.; Behm, H.; Ottenheijm, H.C.J. Application of an isoxazolidine in a stereoselective approach to the fumitremorgin series. J. Org. Chem., 1987, 52(4), 560-564.

[17] Allen, J.D.; van Loevezijn, A.; Lakhai, J.M.; van der Valk, M.; van Tellingen, O.; Reid, G.; Schellens, J.H.; Koomen, G.J.; Schinkel, A.H. Potent and specific inhibition of the breast cancer resistance protein multidrug transporter in vitro and in mouse intestine by a novel analogue of fumitremorgin C. Mol. Cancer Ther., 2002, 1(6), 417-425.

[18] van Loevezijn, A.; Allen, J.D.; Schinkel, A.H.; Koomen, G.J. Inhibition of BCRP-mediated drug efflux by fumitremorgin-type indolyl diketopiperazines. Bioorg. Med. Chem. Lett., 2001, 11 (1), 2932.

[19] Szolomajer-Csikós, O.; Beéry, E.; Kosa, L.; Rajnai, Z.; Jani, M.; Hetényi, A.; Jakab, K.T.; Krajesi, P.; Tóth, G.K. Synthesis and ABCG2-inhitory activity of novel fumitremorgin $\mathrm{C}$ analogs speci- ficity and structure activity correlations. Med. Chem., 2013, 9(4), 494-509.

[20] Guidance for Industry. Bioanalytical Method Validation. http://www.fda.gov/downloads/Drugs/GuidanceComplianceRegula toryInformation/Guidances/UCM070107.pdf (Accessed: Jan. 15, 2013).

[21] Armbruster, D.A.; Tillman, M.D.; Hubbs, L.M. Limit of detection (LQD)/limit of quantitation (LOQ): comparison of the empirical and the statistical methods exemplified with GC-MS assays of abused drugs. Clin. Chem., 1994, 40, 1233-1238.

[22] Zhang, Y.; Huo, M.; Zhou, J.; Xie, S. PKSolver: An add-in program for pharmacokinetic and pharmacodynamic data analysis in Microsoft Excel. Comput. Methods Programs Biomed., 2010, 99(3), 306-314.

[23] Bartos, D.; Görög, S. Recent advances in the impurity profiling of drugs. Curr. Pharm. Anal., 2008, 4(4), 2015-2230. 